\title{
Bestuursbesluit zou vereist moeten zijn bij eigen enquêteverzoek rechtspersoon
}

\author{
Mr.drs.J. van Bekkum*
}

\begin{abstract}
1 Inleiding
In ons huidige recht is uitgangspunt dat rechtspersonen die geen enquêteverzoek tegen zichzelf willen doen toch kunnen worden geconfronteerd met een eigen enquêteverzoek als een van de zelfstandig vertegenwoordigingsbevoegde bestuurders dat namens de rechtspersoon laat indienen. Ik vind dat opmerkelijk. Uitgangspunt zou moeten zijn dat rechtspersonen die geen enquêteverzoek tegen zichzelf willen doen, daarmee ook niet geconfronteerd kunnen worden. Een uitzondering daarop kan worden aanvaard als vanwege een misstand bij de rechtspersoon het bestuur niet komt tot besluitvorming over het doen van een enquêteverzoek en die misstand ook aan het verzoek ten grondslag wordt gelegd. Juridisch-technisch betekent dit dat de Ondernemingskamer bij het in behandeling nemen van een enquêteverzoekschrift op grond van artikel 2:346 lid 1 onderdeel d van het Burgerlijk Wetboek (BW) in beginsel zou moeten vereisen dat aan het verzoek een bestuursbesluit ten grondslag ligt. De Ondernemingskamer zou mijns inziens bij een dergelijk verzoek geen toepassing moeten geven aan de beschikking van de Hoge Raad inzake Sluis. ${ }^{1}$ Ik licht dit in deze bijdrage toe.
\end{abstract}

\section{Aanleiding voor deze bijdrage}

Aanleiding voor dit stuk is de enquêteprocedure inzake Inashco. $^{2}$ Samen met mijn kantoorgenoot mr. Lemstra vertegenwoordigde ik in die procedure Inashco B.V. (hierna: Inashco) bij haar verweer tegen het enquêteverzoek van diezelfde Inashco. In die procedure was sprake van een zelfstandig bevoegde bestuurder die zonder overleg en tegen de wil van zijn medebestuurder een enquêteverzoekschrift liet indienen namens de rechtspersoon. De Ondernemingskamer heeft in haar eindbeschikking niet beslist op het niet-ontvankelijkheidsverweer dat Inashco hiertegen voerde. De cassatietermijn is verstreken zonder dat cassatie werd ingesteld. Tegen deze achtergrond voel ik mij vrij om in deze bijdrage in te gaan op de niet-ontvankelijkheidsproblematiek in de Inashco-zaak. Ik denk dat

\footnotetext{
Mr. drs. J. van Bekkum is advocaat bij Lemstra Van der Korst te Amsterdam en tevens verbonden aan het Onderzoekcentrum Onderneming \& Recht/Van der Heijden Instituut van de Radboud Universiteit Nijmegen.

1. HR 9 juli 1990 , NJ 1991/51 m.nt. Maeijer (Sluis).

2. Hof Amsterdam (OK) 25 maart 2015, ARO 2015/108 (Inashco).
}

het voor volgende zaken met dezelfde problematiek van belang is dat de gedachtevorming hierover in de literatuur verder wordt ontwikkeld. Ook mijn eigen gedachten zijn sinds de Inashco-zaak verder ontwikkeld. Mijn pleidooi in deze bijdrage is dus geen herhaling van ons pleidooi namens Inashco in de procedure.

In de Inashco-zaak waren de volgende feiten van belang. Fondel Holding B.V. (hierna: Fondel Holding) was de indirect enig aandeelhouder van Inashco. Synvase B.V. (hierna: Synvase) had een overeenkomst met Fondel Holding op grond waarvan Synvase - kort gezegd - belang had bij de financiële resultaten van Inashco en de waarde van haar onderneming. In het kader van die overeenkomst waren Fondel Holding en Synvase elk zelfstandig vertegenwoordigingsbevoegd bestuurder van Fondel Development B.V. (hierna: Fondel Development), die op haar beurt een van de twee zelfstandig vertegenwoordigingsbevoegde bestuurders van Inashco was. Aldus had Synvase de mogelijkheid om Inashco via Fondel Development zelfstandig te vertegenwoordigen. Ook de andere bestuurder van Inashco was zelfstandig vertegenwoordigingsbevoegd. Van belang is bovendien dat die andere bestuurder onafhankelijk was van zowel Fondel Holding als Synvase.

Tussen Fondel Holding en Synvase ontstond een conflict. Dat leidde er uiteindelijk toe dat Synvase namens Inashco een enquêteverzoek liet indienen. Synvase had dit van tevoren niet overlegd met de onafhankelijke bestuurder van Inashco noch hem daarvan in kennis gesteld. De onafhankelijke bestuurder was van oordeel dat het indienen van het enquêteverzoek de belangen van Inashco schaadde. Het laten indienen van het enquêteverzoek was dus niet voorafgegaan door een bestuursbesluit en duidelijk was dat het bestuur van Inashco ook achteraf niet zou besluiten het enquêteverzoek te aanvaarden. Slechts een van de twee (indirecte) bestuurders wilde dat het enquêteverzoek werd ingediend.

In de procedure hebben wij onder meer namens Inashco gesteld dat er in dit geval sprake was van misbruik door Synvase van haar (indirecte) zelfstandige vertegenwoordigingsbevoegdheid en dat Inashco om die reden niet-ontvankelijk was. De Ondernemingskamer heeft op die stelling niet beslist. $\mathrm{Zij}$ 
oordeelde dat bij een beslissing onvoldoende belang was, omdat de inhoudelijke beoordeling van het verzoek leidde tot afwijzing daarvan. ${ }^{3}$

Het feit dat de Ondernemingskamer geen beslissing gaf op voormelde stelling lijkt erop te duiden dat de Ondernemingskamer het al dan niet in behandeling nemen van het enquêteverzoek van Inashco een juridisch lastig vraagstuk vond. Dat is het ook. Ik denk echter dat het dat niet zou moeten zijn en geef in deze bijdrage mijn opvatting over hoe het vraagstuk benaderd en opgelost moet worden.

\section{Uitleg en toepassing van de Sluis-beschikking in context}

Rechtspersonen ${ }^{4}$ hebben bij de jongste wijziging van het enquêterecht de mogelijkheid gekregen om een enquêteverzoek tegen zichzelf in te dienen (art. 2:346 lid 1 onderdeel d BW). Voor zover relevant heeft de wetgever daarbij aangegeven dat het verzoek 'moet worden ingediend door een vertegenwoordiger van de rechtspersoon' en dat de rechtspersoon in dat verband 'kan worden vertegenwoordigd door het bestuur en mede afhankelijk van de statuten, door een individuele bestuurder'. ${ }^{5}$

Leijten en Nieuwe Weme hebben gesteld dat de wetgever op dit punt aansluit bij de beschikking van de Hoge Raad inzake Sluis. ${ }^{6}$ In die beschikking bepaalde de Hoge Raad dat, behoudens misbruik van bevoegdheid, een zelfstandig vertegenwoordigingsbevoegde bestuurder bevoegd is om in een enquêteprocedure namens de rechtspersoon een verweerschrift te laten indienen, ook als daaraan geen bestuursbesluit ten grondslag ligt. ${ }^{7}$ Ik meen dat de stelling van Leijten en Nieuwe Weme moet worden genuanceerd. Juist is dat voormelde passage uit de parlementaire geschiedenis niet in strijd is met de Sluisbeschikking. Dat deze daarbij aansluit, lijkt mij echter te sterk gesteld, omdat de wetgever niets stelt over dat aan de vertegenwoordigingshandeling bij indiening geen bestuursbesluit ten grondslag hoeft te liggen. Juist dat is het kenmerkende element van de Sluis-beschikking.

Leijten en Nieuwe Weme stellen met juistheid dat als de Sluisbeschikking zou worden doorgetrokken naar het geval waarin de rechtspersoon een enquêteverzoek tegen zichzelf indient 'in beginsel iedere bestuurder bevoegd zal zijn om namens de ven-

3. Hof Amsterdam (OK) 25 maart 2015, ARO 2015/108 (Inashco), r.o. 3.2. Dit is een praktische wijze van zaaksbehandeling die voor Inashco het beoogde resultaat had. Toch is deze aanpak ook ongelukkig, omdat de Ondernemingskamer het zichzelf heeft toegestaan om een (weliswaar summier) inhoudelijk oordeel uit te spreken over een verzoek namens Inashco, terwijl Inashco mogelijk niet-ontvankelijk was, in welk geval het niet past om toch een inhoudelijk oordeel te geven.

4. Dit geldt enkel voor rechtspersonen als bedoeld in art. 2:344 BW.

5. Kamerstukken II 2010/11, 32887, 3, p. 29.

6. A.F.J.A. Leijten \& M.P. Nieuwe Weme, Het wetsvoorstel aanpassing enquêterecht, in: Geschriften vanwege de Vereniging Corporate Litigation 2011-2012, p. 136.

7. HR 9 juli 1990, NJ 1991/51 m.nt. Maeijer (Sluis), r.o. 3.2 nootschap een verzoekschrift in te dienen'. ${ }^{8}$ Dit geldt dus wel alleen voor bestuurders die, conform het wettelijk uitgangspunt, ${ }^{9}$ zelfstandig vertegenwoordigingsbevoegd zijn.

De vraag is of het wel zo vanzelfsprekend is om voor de situatie waarin de rechtspersoon een enquêteverzoek tegen zichzelf indient aan te sluiten bij de Sluis-beschikking. In de Sluiszaak was het enquêteverzoekschrift ingediend door aandeelhouders van Sluis B.V. (hierna: Sluis). Een van de twee zelfstandig vertegenwoordigingsbevoegde bestuurders stond achter het verzoek. De andere zelfstandig vertegenwoordigingsbevoegde bestuurder was tegen en liet namens Sluis een verweerschrift indienen. Daaraan lag geen bestuursbesluit ten grondslag. De vraag of het verweerschrift in behandeling moest worden genomen, stond niet in de sleutel van de ontvankelijkheid, want die horde was al genomen.

In deze situatie was er in redelijkheid niets op tegen dat de Ondernemingskamer het verweerschrift toch in behandeling nam. Zodoende kon de Ondernemingskamer kennisnemen van alle standpunten binnen het bestuur van de rechtspersoon, wat relevant was bij de inhoudelijke behandeling van het verzoek. Dat geldt temeer omdat het bevelen van een onderzoek een discretionaire bevoegdheid is van de Ondernemingskamer en zij bij de beslissing om al dan niet een onderzoek te bevelen de belangen van alle betrokken partijen moet afwegen. ${ }^{10}$ In de Sluis-beschikking overwoog de Hoge Raad in dit verband expliciet dat de Ondernemingskamer 'onverschillig of namens de rechtspersoon verweer wordt gevoerd, dient te onderzoeken of een verzoek als bedoeld in art. 2:345 BW op grond van de gestelde feiten toewijsbaar is' ${ }^{11}$ Gegeven deze taak past het niet dat de Ondernemingskamer geen kennis zou kunnen nemen van de inhoud van een verweerschrift dat namens de rechtspersoon is ingediend, ook als daaraan geen bestuursbesluit ten grondslag ligt. In de Sluis-zaak verwierp de Ondernemingskamer dan ook de (kennelijke) stelling van de verzoekende aandeelhouders dat de Ondernemingskamer geen kennis behoorde te nemen van het verweerschrift. ${ }^{12}$ Dit oordeel bleef in cassatie in stand.

Ik schat in dat dit hoe dan ook de beslissing van de Ondernemingskamer zou zijn geweest. Ook als de verwerende bestuurder niet zelfstandig vertegenwoordigingsbevoegd zou zijn geweest. In de Sluis-zaak is de zelfstandige vertegenwoordigingsbevoegdheid van de verwerende bestuurder door de Ondernemingskamer mogelijk slechts aangegrepen als het

8. Leijten \& Nieuwe Weme2011-2012, p. 136, zie ook p. 139 en 140.

9. Zie bijv. art. 2:240 lid 2 BW

10. T\&C Burgerlijk Wetboek, Boek 2, Deventer: Kluwer 2013, art. 2:350, aant. 2.

11. HR 9 juli 1990, NJ 1991/51 m.nt. Maeijer (Sluis), r.o. 3.2. Kortom, ook als het verweerschrift niet namens Sluis was ingediend, was het van belang dat de Ondernemingskamer het daarin gestelde zou meewegen in haar beslissing.

12. Zie r.o. 4 van de beschikking van de Ondernemingskamer in de Sluiszaak, zoals die blijkt uit HR 9 juli 1990, NJ 1991/51 m.nt. Maeijer (Sluis). 


\section{Maandblad}

Ondernemingsrecht

voorhanden zijnde formele haakje om de kennisname van het verweerschrift te rechtvaardigen. Buiten de specifieke feiten en omstandigheden in de Sluis-zaak zijn andere rechtvaardigingen denkbaar en in de praktijk ook gebruikt. Dat blijkt onder meer uit twee gevallen waarin de Ondernemingskamer verweerschriften in behandeling heeft genomen die werden ingediend op instructie van een van de twee bestuurders van de verwerende rechtspersoon zonder dat die bestuurder zelfstandig vertegenwoordigingsbevoegd was. In de Maxx Holdingbeschikking overwoog de Ondernemingskamer dat in de omstandigheden van dat geval in redelijkheid door de verzoeker geen beroep kon worden gedaan op de onbevoegdheid van de bestuurder om zelfstandig namens de rechtspersoon verweer te laten voeren. ${ }^{13}$ In de Smit Transformatoren-beschikking oordeelde de Ondernemingskamer dat een beslissing op de stellingen over en weer, dat tegenstrijdige verweerschriften niet bevoegd namens de rechtspersoon waren ingediend, achterwege kon blijven, omdat de verwerende rechtspersoon niet in enig (processueel) belang werd geschaad als de Ondernemingskamer kennis zou nemen van beide verweerschriften. ${ }^{14}$ Deze ten opzichte van de Sluis-beschikking wat creatievere overwegingen van de Ondernemingskamer dienden hetzelfde doel als in de Sluis-zaak: kennisname door de Ondernemingskamer van alle standpunten binnen het bestuur van de verweerder.

Ondanks dat de Hoge Raad in de Sluis-beschikking in algemene bewoordingen lijkt te stellen dat op het laten verrichten van proceshandelingen namens de rechtspersoon de gewone vertegenwoordigingsregels van toepassing zijn, denk ik dat de context waarin en het doel waarmee de Sluis-beschikking werd gewezen niet uit het oog mogen worden verloren. Los van de kritiek die bestaat op de toepassing van de gewone vertegenwoordigingsregels bij vertegenwoordiging in rechte, ${ }^{15}$ leent de Sluis-beschikking van de Hoge Raad zich mijns inziens niet om te worden doorgetrokken naar de situatie waarin de rechtspersoon een enquêteverzoek tegen zichzelf indient en de Ondernemingskamer moet oordelen over het in behandeling nemen van dat verzoek. De Hoge Raad heeft speelruimte om zonder te hoeven terugkomen van de Sluis-beschikking deze niet door te trekken naar die situatie. In de Sluis-beschikking heeft de Hoge Raad letterlijk genomen enkel overwogen dat de gewone vertegenwoordigingsregels meebrachten dat verzoekers zich niet met vrucht erop konden beroepen dat 'een - geldig - bestuursbesluit om verweer te voeren ontbreekt'. ${ }^{16}$ Dat laat voor de Hoge Raad de mogelijkheid open om voor het laten indienen van een verzoekschrift door de rechtspersoon in beginsel wel een geldig bestuursbesluit te vereisen. Daar is reden toe.

13. Hof Amsterdam (OK) 25 april 2002, JOR 2002/219 (Maxx Holding), r.o. 3.2.

14. Hof Amsterdam (OK) 5 oktober 2005, JOR 2005/296 m.nt. Leijten (Smit Transformatoren), r.o. 3.2.

15. Zie daarover kort: Leijten \& Nieuwe Weme2011-2012, p. 136.

16. HR 9 juli 1990, NJ 1991/51 m.nt. Maeijer (Sluis), r.o. 3.2, cursivering toegevoegd.
4 Geen toepassing Sluis-beschikking bij enquêteverzoek rechtspersoon tegen zichzelf

De Inashco-zaak was een geval waarin de rechtspersoon een enquêteverzoek tegen zichzelf indiende. Daaraan lag geen bestuursbesluit ten grondslag. Aangezien de wil van een rechtspersoon (primair) wordt gevormd door de besluiten van zijn bestuur, ${ }^{17}$ betekent dit dat Inashco werd geconfronteerd met een enquêteverzoek van haarzelf zonder dat zij dit wilde. Anders dan bij de Sluis-beschikking stond de vraag of de Ondernemingskamer het processtuk van Inashco in behandeling moest nemen in de sleutel van de ontvankelijkheid.

\subsection{Indien een conflict binnen het bestuur onderwerp is van het enquêteverzoek}

Het ontbreken van de wil bij Inashco hoefde er niet per definitie aan in de weg te staan dat de Ondernemingskamer het verzoekschrift in behandeling nam. Dat geldt ongeacht het antwoord op de vraag of de bestuurder die het verzoekschrift liet indienen zelfstandig vertegenwoordigingsbevoegd was. Dat blijkt uit de Hoffmann-beschikking. In die beschikking had Hoffmann jr. als aandeelhouder van Hoffmann Beheer B.V. (hierna: Hoffmann Beheer) een enquêteverzoekschrift laten indienen tegen Hoffmann Beheer, waarin hij samen met Hoffmann sr. bestuurder was (althans als zodanig door de Ondernemingskamer werd aangemerkt ${ }^{18}$ ). Daarnaast had Hoffmann jr. als niet zelfstandig vertegenwoordigingsbevoegde bestuurder van Hoffmann Beheer een enquêteverzoekschrift laten indienen tegen dochtermaatschappij Hoffmann Bedrijfsrecherche B.V. (hierna: Hoffmann Bedrijfsrecherche). Bij Hoffmann Bedrijfsrecherche was Hoffmann sr. enig bestuurder. Laatstgenoemde beriep zich er namens Hoffmann Bedrijfsrecherche op dat het enquêteverzoek van haar aandeelhouder Hoffmann Beheer niet-ontvankelijk was, omdat Hoffmann jr. niet zelfstandig bevoegd was om Hoffmann Beheer te vertegenwoordigen. De Ondernemingskamer verwierp deze stelling, omdat aan het verzoek van Hoffmann Beheer het beleid van Hoffmann sr. ten grondslag werd gelegd, zodat Hoffmann sr. namens Hoffmann Bedrijfsrecherche in redelijkheid geen beroep toe[kwam] op onbevoegdheid van Hoffmann jr.' om Hoffmann Beheer zelfstandig te vertegenwoordigen. ${ }^{19}$

Kortom, in de Hoffmann-zaak was er een conflict in het bestuur van Hoffmann Beheer dat doorwerkte in het beleid en de gang van zaken bij Hoffmann Bedrijfsrecherche. Dat conflict was onderwerp van het enquêteverzoek en stond tegelijkertijd in de weg aan besluitvorming van het bestuur van Hoffmann Beheer over het laten indienen van een enquêteverzoek tegen Hoffmann Bedrijfsrecherche. In zo'n situatie hoeft de Ondernemingskamer niet af te zien van het in behandeling

17. Voor zover dit niet vanzelfsprekend is, zie HR 19 oktober 2001, JOR 2002/1 m.nt. Blanco Fernández (Utrechts Monumentenfonds), r.o. 3.4.4 en de eerste twee zinnen van de noot van Blanco Fernández.

18. Hof Amsterdam (OK) 8 oktober 1998, JOR 1998/166 (Hoffmann), r.o. 4.1 .

19. Hof Amsterdam (OK) 8 oktober 1998, JOR 1998/166 (Hoffmann), r.o. 4.1. Vgl. Hof Amsterdam (OK) 25 april 2002, JOR 2002/219 (Maxx Holding). 
nemen van het enquêteverzoek vanwege het ontbreken van een besluit van het bestuur van de verzoeker tot het indienen van een enquêteverzoekschrift. Uit de Hoffmann-zaak blijkt dat ook het ontbreken van zelfstandige vertegenwoordigingsbevoegdheid daaraan niet in de weg hoeft te staan. Juist niet, zou ik zeggen.

\subsection{Indien er geen conflict speelt binnen het bestuur}

Dit ligt anders als er geen conflict speelt binnen het bestuur van de verzoekende rechtspersoon en er een besluit ontbreekt van die rechtspersoon om het enquêteverzoek in te dienen. In dat geval is het onderwerp van het enquêteverzoek niet de oorzaak van het ontbreken van dat besluit.

Dit was het geval in de Inashco-zaak. Daar speelde een conflict tussen een van de (indirecte) bestuurders en de enig aandeelhouder van Inashco. Dat conflict speelde zich af buiten het beleid en de gang van zaken bij Inashco en bij dat conflict was de andere (onafhankelijke) bestuurder van Inashco ook niet betrokken. Die andere bestuurder kon dus zonder last van enig persoonlijk tegenstrijdig belang deelnemen aan besluitvorming van het bestuur van Inashco over de vraag of het in het belang was van Inashco en haar onderneming om een enquêteverzoek tegen Inashco te laten indienen. Ik meen dat de Ondernemingskamer het in zo'n geval moet respecteren als de rechtspersoon niet heeft besloten om een enquêteverzoek tegen zichzelf te laten indienen. Ondanks dat dit op grond van de Sluis-beschikking, behoudens misbruik van bevoegdheid, wel zou kunnen, zou de Ondernemingskamer in zo'n geval niet enkel vanwege de zelfstandige vertegenwoordigingsbevoegdheid van de verzoekende bestuurder moeten kunnen overgaan tot het in behandeling nemen van het verzoek. Als dat wel zou kunnen, zou dat materieel betekenen dat iedere zelfstandig vertegenwoordigingsbevoegde bestuurder enquêtegerechtigd is. Artikel 2:346 lid 1 onderdeel d BW kent de enquêtebevoegdheid echter enkel toe aan de rechtspersoon, niet aan bestuurders. Bovendien vormt een 'alleingang' van een zelfstandig vertegenwoordigingsbevoegde bestuurder bij het laten indienen van een enquêteverzoekschrift op zichzelf een gegronde reden voor twijfel aan de juistheid van het beleid en de gang van zaken bij de verzoekende rechtspersoon. Aangenomen dat er meerdere bestuurders zijn, handelt de verzoekende bestuurder immers in strijd met het uitgangspunt van collegiaal bestuur door van zijn zelfstandige vertegenwoordigingsbevoegdheid gebruik te maken in de wetenschap dat het bestuur van de rechtspersoon daar niet achterstaat, althans zonder de wetenschap dat het bestuur daar wel achterstaat. Het lijkt mij bij uitstek de taak van de Ondernemingskamer om geen gevolg te geven aan dergelijke verzoeken. De Ondernemingskamer is immers het forum waar de gezonde interne verhoudingen binnen de rechtspersoon worden bewaakt. Daar zouden geen verzoekschriften moeten worden behandeld die enkel konden worden ingediend door het schenden van de interne verhoudingen van de rechtspersoon, zonder dat daarvoor een voldoende rechtvaardiging bestaat (die wel bestond in de Hoffmann-zaak).
Cynici zullen wellicht stellen dat een zelfstandig vertegenwoordigingsbevoegde bestuurder het niet-ontvankelijkheidsrisico eenvoudig kan omzeilen door in het verzoekschrift op te nemen dat er sprake is van een conflict in het bestuur dat besluitvorming over het doen van het enquêteverzoek in de weg stond. Zo eenvoudig is dat echter niet. De Ondernemingskamer zal moeten toetsen of die stelling juist is, zeker als daartegen verweer wordt gevoerd. Als er geen (voldoende) redelijke grond is voor het innemen van die stelling, zal de Ondernemingskamer de stelling niet honoreren en de verzoeker niet-ontvankelijk verklaren. In dat geval komt de Ondernemingskamer niet toe aan de behandeling van de overige inhoud van het onbevoegd ingediende enquêteverzoekschrift.

Het lijkt mij overigens waarschijnlijk dat in de meeste gevallen waarin een zelfstandig vertegenwoordigingsbevoegde bestuurder in een meerhoofdig bestuur op eigen houtje een enquêteverzoekschrift laat dienen, er een serieus conflict zal spelen binnen het bestuur. Uit de Inashco-zaak blijkt echter dat dit niet steeds het geval zal zijn. Voor die gevallen is van belang dat de hoofdregel zal zijn dat voor het laten indienen van het enquêteverzoekschrift door de rechtspersoon zelf in beginsel een bestuursbesluit is vereist.

\subsection{Artikel 2:15 lid 3 onderdeel b BW}

Ik word in deze opvatting gesterkt door artikel 2:15 lid 3 onderdeel b BW. Dat artikel biedt een rechtspersoon de mogelijkheid een vordering in te stellen tegen zichzelf tot vernietiging van een besluit van (een van de organen van) de rechtspersoon. Net als bij de actie op grond van artikel 2:346 lid 1 onderdeel d BW biedt artikel 2:15 lid 3 onderdeel b BW de rechtspersoon dus de mogelijkheid om zijn interne zaken voor te leggen aan de rechter.

Voor de vordering op grond van artikel 2:15 lid 3 onderdeel b $\mathrm{BW}$ is niet voldoende dat deze namens de rechtspersoon wordt ingesteld door een zelfstandig vertegenwoordigingsbevoegde bestuurder. Deze vordering moet worden 'ingesteld krachtens bestuursbesluit' (art. 2:15 lid 3 onderdeel b BW). Dit lijkt mij een juist voorschrift. Het stelt zeker dat de rechtspersoon die de vordering tegen zichzelf aanhangig maakt, dat ook echt wil.

Ik heb gezocht naar enige toelichting op dit voorschrift in de parlementaire geschiedenis, maar niets gevonden. ${ }^{20}$ De reden hiervoor zou kunnen zijn de vanzelfsprekendheid die het voorschrift mijns inziens kenmerkt.

In de literatuur ben ik op één passage gestuit waarin aandacht wordt geschonken aan het 'krachtens bestuursbesluit'-voorschrift. De Monchy en Timmerman schreven in hun preadvies over de nieuwe algemene bepalingen van Boek 2 BW dat het voorschrift nodig is, omdat als het voorschrift er niet zou zijn:

20. Kamerstukken II 1982/83, 17725, 2, p. 12-13, en 3, p. 62. 


\section{Maandblad}

Ondernemingsrecht

'één volledig vertegenwoordigingsbevoegde bestuurder van een meerhoofdig bestuursorgaan een procedure namens de rechtspersoon [zou] kunnen starten tot vernietiging van een besluit van de rechtspersoon. Dit lijkt niet acceptabel. Vóór het starten van een vernietigingsprocedure behoort steeds tenminste een meerderheid in het bestuurscollege zich te hebben uitgesproken (...).'21

Ook merken De Monchy en Timmerman op dat het geval dat de rechtspersoon een vernietigingsprocedure tegen een eigen besluit start, moet worden onderscheiden van het geval in de Sluis-zaak waar namens de rechtspersoon een verweerschrift werd ingediend. ${ }^{22}$ Ik sluit mij graag bij De Monchy en Timmerman aan.

Tegen deze achtergrond is het een gemis dat de wetgever bij de jongste herziening van het enquêterecht geen aandacht heeft besteed aan de vraag of een bestuursbesluit ten grondslag moet liggen aan het verzoek van de rechtspersoon op grond van artikel 2:346 lid 1 onderdeel d BW. Een reflectie in dit verband op artikel 2:15 lid 3 onderdeel b BW en een bewuste keuze voor het wel of niet vereisen van een bestuursbesluit waren mijns inziens op hun plaats geweest. Ik hoop dat de Ondernemingskamer deze leemte die de wetgever heeft gelaten, zal invullen en in lijn met artikel 2:15 lid 3 onderdeel b BW zal oordelen dat een bestuursbesluit in beginsel wel is vereist. Het feit dat artikel 2:346 lid 1 onderdeel d BW dat niet expliciet vereist, zou in het licht van al het voorgaande niet doorslaggevend moeten zijn.

\subsection{Tegenstrijdige rechtsgeldige proceshandelingen rechtspersoon}

Een bijkomend voordeel van het vereisen van een bestuursbesluit bij het indienen van een enquêteverzoek door de rechtspersoon zelf is dat dit de door Leijten en Nieuwe Weme geschetste problematiek oplost van verschillende zelfstandig vertegenwoordigingsbevoegde bestuurders die (rechtsgeldig) tegenstrijdige proceshandelingen laten verrichten. ${ }^{23}$ Als een bestuursbesluit is vereist, is het bijvoorbeeld niet meer mogelijk dat de ene zelfstandig vertegenwoordigingsbevoegde bestuurder een enquêteverzoek laat indienen, dat een andere zelfstandig vertegenwoordigingsbevoegde bestuurder weer laat intrekken (waarbij vanzelfsprekend ook de intrekking door een bestuursbesluit zou moeten worden gedragen).

\subsection{De 'misbruik van bevoegdheid'-optie is geen volwaardigalternatief}

Overigens zou de Ondernemingskamer het door mij bepleite resultaat ook kunnen bereiken door toepassing te geven aan de Sluis-beschikking, maar dan te oordelen dat in een geval als bij Inashco sprake is van misbruik van bevoegdheid door de ver-

21. C.W. de Monchy \& L. Timmerman, De nieuwe algemene bepalingen van Boek 2 BW. Preadvies van de Vereeniging 'Handelsrecht', Zwolle: W.E.J. Tjeenk Willink 1991, p. 90.

22. Idem.

23. Leijten \& Nieuwe Weme2011-2012, p. 139-140. zoekende bestuurder. Ik vind daar veel voor te zeggen. Een bestuurder met zelfstandige vertegenwoordigingsbevoegdheid heeft deze bevoegdheid niet gekregen om namens de rechtspersoon te kunnen doen wat de bestuurder zelf wil. De zelfstandige vertegenwoordigingsbevoegdheid is gegeven om deze te gebruiken in het handelsverkeer in overeenstemming met de (impliciete of expliciete) besluiten van het bestuur van de rechtspersoon. Door deze bevoegdheid in afwijking daarvan te gebruiken voor een ander doel, namelijk om de wil van de bestuurder zelf te dienen, is er beargumenteerbaar sprake van misbruik van bevoegdheid in de zin van artikel 3:13 BW. Een complicatie hierbij is echter dat rechters niet snel geneigd zijn te oordelen dat sprake is van misbruik van bevoegdheid. In zijn noot bij de Sluis-beschikking schrijft Maeijer hierover dat de uitzondering 'misbruik van bevoegdheid' op de vertegenwoordigingsregels 'niet te snel en te ruimhartig [moet] worden toegestaan'. ${ }^{24} \mathrm{Om}$ deze reden verdient het volgen van de Sluisbeschikking bij enquêteverzoeken door de rechtspersoon niet mijn voorkeur.

\section{Conclusie}

De Sluis-beschikking van de Hoge Raad leent zich mijns inziens niet om te worden doorgetrokken naar de situatie waarin de rechtspersoon een enquêteverzoek tegen zichzelf indient en waarin de Ondernemingskamer moet oordelen over het in behandeling nemen van dat verzoek. In zo'n geval zou de Ondernemingskamer voor het in behandeling nemen van het verzoek in beginsel moeten vereisen dat daaraan een bestuursbesluit ten grondslag ligt. Op dat beginsel kan een uitzondering worden aanvaard als vanwege een misstand bij de rechtspersoon het bestuur niet komt tot besluitvorming over het doen van een enquêteverzoek en die misstand ook aan het verzoek ten grondslag wordt gelegd.

24. Noot Maeijer, par. 3, bij HR 9 juli 1990, NJ 1991/51 m.nt. Maeijer (Sluis). 